\title{
Spelling-sound regularity effects on eye fixations in reading
}

\author{
SARA C. SERENO \\ University of Glasgow, Glasgow, Scotland \\ and \\ KEITH RAYNER \\ University of Massachusetts, Amherst, Massachusetts
}

\begin{abstract}
An interaction of word frequency and word regularity has typically been observed in naming and lexical decision experiments in which, in addition to an overall effect of word frequency, responses to low-frequency exception words are slower than those to low-frequency regular words, while no such difference occurs with high-frequency words. The only eye movement study to examine this effect in reading (Inhoff \& Topolski, 1994) reported only transient effects of regularity. In the present experiment, we examined the frequency $\times$ regularity interaction using different stimuli than those of Inhoff and Topolski and also varied the parafoveal preview of the target word prior to fixation. When the preview was valid, the frequency $\times$ regularity interaction appeared. However, with an invalid preview, the effect of regularity disappeared. The results suggest that the activation of phonological codes is a very early component of reading.
\end{abstract}

How important are spelling-sound regularities in word recognition and reading? Many word recognition studies have shown that spelling-sound regularities influence naming and lexical decision times when target words are presented in isolation (see, e.g., Bauer \& Stanovich, 1980; Glushko, 1979; Inhoff \& Topolski, 1994; Seidenberg, Waters, Barnes, \& Tanenhaus, 1984; Stanovich \& Bauer, 1978; Waters \& Seidenberg, 1985). Although the pattern of results across studies is somewhat complex (depending on specific characteristics of the stimuli and the task used), the general conclusion is that regularity has little effect on high-frequency (HF) words, but that responses to low-frequency (LF) exception words are slowed relative to LF regular words. Regular words, such as time, have predictable pronunciations because all words that end in ime rhyme with each other (e.g., dime and slime). On the other hand, exception words, such as good, are not predictable on the basis of their spelling pattern, either because word neighbors that share the ood coda (e.g., food and mood) do not rhyme or, in the case of words like doubt or weird, that have no such neighbors, the spelling--sound mapping is idiosyncratic. If phonological information is

This research was conducted while S.C.S. was supported by a McDonnell-Pew Postdoctoral Research Fellowship at the University of Oregon and K.R. was supported by a Research Scientist Award (MH01255) from the National Institute of Mental Health and Grants HD17246 and HD26765 from the National Institutes of Health. We thank Derek Besner, Charles Clifton, John Henderson, Albrecht Inhoff, and an anonymous reviewer for their helpful comments, and Charles Clifton for his technical assistance. Correspondence should be addressed to S. C. Sereno, Psychology Department, 53 Hillhead Street, University of Glasgow, Glasgow G12 8QF, Scotland, U.K. (e-mail: ssereno@psy.gla.ac.uk). important in recognizing words, exception words should be more difficult to process than regular words. For HF words, the meaning of the word is apparently accessed from its orthography independent of its phonology; for LF words, phonological information plays a greater, detectable role.

Do these effects generalize to normal reading? Only one study has examined spelling-sound regularities in the context of reading (Inhoff \& Topolski, 1994, Experiment 2). Inhoff and Topolski monitored participants' eye movements as they read sentences containing HF and LF regular and exception words. They found robust effects of word frequency: LF words were fixated longer than HF words, a finding consistent with a great deal of prior eye movement research (e.g., Henderson \& Ferreira, 1990; Hyönä \& Olson, 1995; Inhoff \& Rayner, 1986; Just \& Carpenter, 1980; Rayner \& Duffy, 1986; Rayner \& Raney, 1996; Rayner, Sereno, \& Raney, 1996; Schilling, Rayner, \& Chumbley, 1998; Sereno, 1992). Inhoff and Topolski, however, failed to find an interaction between frequency and regularity, as prior naming and lexical decision experiments had. These results merit further investigation.

Inhoff and Topolski examined both first-fixation and gaze duration measures on target words. First-fixation duration is an average of the first fixations made on words, disregarding any additional fixations; gaze duration is the average of the sum of all fixations made on a word prior to an eye movement to another word. While most words are typically fixated only once (in which case first-fixation and gaze duration are the same), gaze duration has generally been favored in eye movement studies as the best estimate of processing time on a word. In their first-fixation data, Inhoff and Topolski found overall effects of frequency and regularity but no significant interaction. The 
pattern of regularity differences, however, did correspond to that of prior word recognition studies: The difference between regular and exception words was $6 \mathrm{msec}$ for HF words and $17 \mathrm{msec}$ for LF words. With gaze duration, they found only a main effect of frequency. The effect of regularity had decreased to $6 \mathrm{msec}$ and did not approach significance. Inhoff and Topolski concluded that effects of phonological regularity were relatively transient. On the other hand, other experiments reported by Inhoff and Topolski provided evidence for the early use of phonology during reading.

In the present study, we examined the interaction between frequency and regularity, but with certain critical changes in stimuli and design from Inhoff and Topolski (1994). Inhoff and Topolski used stimuli from Seidenberg et al.'s (1984) Experiment 3. They chose 10 words from each of the four word conditions (HF regular, HF exception, LF regular, LF exception) and embedded these as targets in separate sentences. These words, however, sampled many different syntactic categories that varied systematically across conditions (e.g., HF words were mostly verbs, with some determiners, whereas LF words were mostly nouns, with some verbs and adjectives). In our study, we used 24 sets of words from the four conditions (mostly nouns and a few verbs and adjectives). Each set of four words appeared within identical sentence frames so that sentence structure and, hence, viewing conditions were controlled across conditions.

Additionally, in our design, we varied whether readers received a valid parafoveal preview of the target word prior to fixating it. Reliable preview effects have been widely demonstrated (Balota, Pollatsek, \& Rayner, 1985; Blanchard, Pollatsek, \& Rayner, 1989; Inhoff \& Rayner, 1986; Kennison \& Clifton, 1995; Rayner, 1975; Rayner, Well, Pollatsek, \& Bertera, 1982). When participants receive an invalid preview of the to-be-fixated word (i.e., something other than the target initially occupies its location, e.g., a letter string or a string of Xs), their fixation time on that word generally increases by $20-50 \mathrm{msec}$. Our rationale in using the preview manipulation was to more closely approximate the situation in naming and lexical decision where words presented in isolation are viewed only foveally. With an uninformative preview, more robust regularity effects might emerge, particularly in gaze duration.

\section{METHOD}

\section{Participants}

Thirty-two members of the University of Massachusetts community were paid $\$ 5$ to participate in the experiment. They either had normal, uncorrected vision or wore soft contact lenses. They were all naive concerning the purpose of the experiment.

\section{Apparatus}

Eye movements were recorded via a Stanford Research Institute Dual Purkinje Eyetracker (Generation 3), which has a resolution of less than 10 min of arc. Although viewing was binocular, recording was from the right eye. The output of the eyetracker was sampled every millisecond by a 486 computer that was also interfaced to a
Conrac 9317 RGB Auto-Trak monitor on which the sentences were displayed. At a viewing distance of $63 \mathrm{~cm}, 3$ letters subtended $1^{\circ}$ of visual angle. All sentences were presented in a nonproportional font on a single line with a maximum of 60 characters. Luminance of the monitor was adjusted to a comfortable level and held constant throughout the experiment. The monitor had a P22 phosphor with the characteristic that display blanking resulted in a drop to $10 \%$ of maximum brightness in $0.06 \mathrm{msec}$ for the cyan characters that were used.

\section{Materials}

The target words were $24 \mathrm{HF}$ regular words, $24 \mathrm{HF}$ exception words, $24 \mathrm{LF}$ regular words, and $24 \mathrm{LF}$ exception words with average frequencies of $150,146,6$, and 6 per million, respectively, as computed from the Francis and Kučera (1982) norms. Target words were all 4,5 , or 6 letters long (average $=4.75$ ) and word length was equated across conditions. Sentence frames were prepared so that one of each type of target could be inserted. For example, the sentence frame "It was a lonely__ during those eight days." could accommodate the HF regular word race, the HF exception word tour, the LF regular word hike, and the LF exception word isle. For each set of four targets, four such sentence frames were constructed, giving rise to a total of 96 sentence frames for the 24 sets of targets. A complete listing of the materials appears in the Appendix. The targets for the present experiment were a subset of materials taken from a lexical decision experiment that used 72 sets of $\mathrm{HF}$ and LF regular and exception words. In that experiment, a significant frequency $X$ regularity interaction was obtained (Sereno, Rayner, \& Posner, 1998).

\section{Design}

The 2 (preview: valid vs. invalid) $\times 2$ (frequency: HF vs. LF) $\times 2$ (regularity: regular vs. exception) design gave rise to eight experimental conditions. With a total of 96 sentences, there were 12 items per condition. With a total of 32 participants, there were 4 participants per item per condition. Because there were four possible sentence frames generated for a set of four targets, all participants were presented with all of the target words.

\section{Procedure}

When a participant arrived for the experiment, a bite bar was prepared to minimize head movements. The initial calibration of the eyetracking system generally required about $5 \mathrm{~min}$. A calibration display appeared between every trial so that calibration could be checked throughout the experiment. Participants were asked to read sentences as their eye movements were monitored. They were instructed to read for comprehension.

Participants read eight practice sentences to become familiar with the procedure. Prior to reading each sentence, participants looked at the leftmost calibration box, which marked the first character position of the sentence. The experimenter checked to ensure that the participant was fixated there, gave a ready signal, then pressed a button to present the sentence. After reading the sentence, the participant pressed a button for the next trial. Then, either the sequence resumed without interruption or the participant was asked a yes-no comprehension question. After the practice sentences, participants read the 96 experimental sentences. Questions were asked on approximately one third of the trials. Participants had no difficulty answering the questions correctly.

On half of the trials (valid preview trials), the sentences appeared normally with one of the target words in the target location. On the other half of the trials (invalid preview trials), a letter string equal in length to the target initially occupied the target location. The letter string was generated based on the probability that a given letter appears in a given letter position of four-, five-, and six-letter words (Mayzner \& Tresselt, 1965). Thus, many of these letter strings, though not all, were somewhat "wordlike." For example, fhmt, ched, kesk, and nreh were the preview letter strings used with the race, tour, hike, and isle set described above. There was no letter overlap 
Table 1

Mean First-Fixation Duration and Gaze Duration (in Milliseconds) for HF and LF Regular and Exception Words as a Function of Parafoveal Preview

\begin{tabular}{lccccc}
\hline & \multicolumn{2}{c}{ Valid Preview } & & \multicolumn{2}{c}{ Invalid Preview } \\
\cline { 2 - 3 } \cline { 5 - 6 } & Regular & Exception & & Regular & Exception \\
\hline First-fixation duration & & & & & \\
LF & 267 & 283 & & 292 & 294 \\
HF & 257 & 260 & & 283 & 277 \\
Gaze duration & & & & \\
LF & 281 & 306 & & 320 & 326 \\
HF & 273 & 278 & & 303 & 296 \\
\hline
\end{tabular}

Note - LF, low frequency; HF, high frequency.

between a given preview letter string and its four possible targets. An invisible boundary located between the final letter of the word preceding the target and the space before the target was established in each sentence. When a reader's eye movement crossed this boundary, the letter string was replaced with the appropriate target word (see Rayner, 1975, for a description of the boundary technique). This change was accomplished within $7.7 \mathrm{msec}$. Because the change took place during the saccade, it was not noticed by the readers. Valid and invalid preview trials were intermixed and the sentences were presented in a different random order to each participant.

\section{RESULTS}

We examined first-fixation and gaze duration times on the targets. ${ }^{1}$ The target region included the space before the word and the word itself. Data were excluded from analyses for the following reasons: (1) There was a blink or a track loss; (2) the display change was triggered on the word before the target by a momentary intrusion into the target region as a result of dynamic overshoot of the saccade (Becker, 1989); and (3) readers initially or completely skipped the target word. Altogether, $25 \%$ of the data were eliminated, leaving 9 data points per condition on average.

\section{First-Fixation Duration}

The first-fixation duration data are shown in Table 1. A 2 (preview: valid vs. invalid) $\times 2$ (frequency: HF vs. $L F$ ) $\times 2$ (regularity: regular vs. exception) analysis of variance (ANOVA) yielded main effects of preview $\left[F_{1}(1,31)=\right.$ $26.50, M S_{\mathrm{e}}=909, p<.001 ; F_{2}(1,95)=39.83, M S_{\mathrm{e}}=$ $1,907, p<.001]$ and frequency $\left[F_{1}(1,31)=13.41, M S_{\mathrm{e}}=\right.$ $\left.1,050, p<.001 ; F_{2}(1,95)=21.80, M S_{\mathrm{e}}=2,063, p<.001\right]$. Readers' first fixations were shorter both when the preview was valid $(267 \mathrm{msec}$ ) versus invalid $(286 \mathrm{msec})$ and when the target was a HF $(269 \mathrm{msec})$ versus a LF word $(284 \mathrm{msec})$. Both of these results replicate a number of previous studies. The effect of regularity was not significant $\left[F_{1}(1,31)=2.52, M S_{\mathrm{e}}=341, p=.12 ; F_{2}(1,95)=\right.$ $\left.1.28, M S_{\mathrm{e}}=341, p>.25\right]$. The frequency $\times$ regularity interaction was marginal by participants $\left[F_{1}(1,31)=3.5\right.$, $\left.M S_{\mathrm{e}}=462, p=.07\right]$ and nonsignificant by items $\left[F_{2}(1,95)=1.53, M S_{\mathrm{e}}=2,720, p>.25\right]$. In addition, the preview $\times$ frequency interaction and the three-way inter- action were both nonsignificant $\left(F_{\mathbf{S}}<1\right)$. However, since regularity interacted with preview $\left[F_{1}(1,31)=6.53, M S_{\mathrm{e}}=\right.$ $\left.358, p<.05 ; F_{2}(1,95)=3.55, M S_{\mathrm{e}}=1,787, p=.06\right]$, we examined the valid and invalid preview conditions in separate 2 (frequency) $\times 2$ (regularity) ANOVAs.

In the valid preview condition, there were significant effects of frequency $\left[F_{1}(1,31)=10.10, M S_{\mathrm{e}}=881, p<.01\right.$; $\left.F_{2}(1,95)=13.03, M S_{\mathrm{e}}=1,640, p<.001\right]$ and regularity $\left[F_{1}(1,31)=9.39, M S_{\mathrm{e}}=321, p<.01 ; F_{2}(1,95)=5.59\right.$, $\left.M S_{\mathrm{e}}=1,721, p<.05\right]$. First fixations were shorter for $\mathrm{HF}$ $(259 \mathrm{msec})$ than for LF words $(275 \mathrm{msec})$ and shorter for regular $(262 \mathrm{msec})$ than for exception words $(272 \mathrm{msec})$. The frequency $\times$ regularity interaction was marginally significant by participants $\left[F_{1}(1,31)=3.40, M S_{\mathrm{e}}=388\right.$, $p=.07]$, but not significant by items $\left[F_{2}(1,95)=1.08\right.$, $\left.M S_{\mathrm{e}}=1,543, p>.30\right]$. Contrasts revealed that $\mathrm{LF}$ regular and exception words differed significantly [267 vs. $283 \mathrm{msec}$, respectively; $F_{1}(1,31)=10.72, M S_{\mathrm{e}}=388, p<$ $\left..01 ; F_{2}(1,95)=6.25, M S_{\mathrm{e}}=1,543, p<.05\right]$, while no such difference was present with HF words [ $257 \mathrm{vs} .260 \mathrm{msec}$, respectively; $F_{1}<1 ; F_{2}(1,95)=1.06, M S_{\mathrm{e}}=1,543, p>$ .30].

In the invalid preview condition, there was a significant effect of frequency $\left[F_{1}(1,31)=4.73, M S_{\mathrm{e}}=1,144\right.$, $\left.p<.05 ; F_{2}(1,95)=10.60, M S_{\mathrm{e}}=2,229, p<.01\right]$. Again, first fixations were shorter for HF (280 msec) than for LF (293 msec) words. The effect of regularity was nonsignificant $(F \mathrm{~s}<1)$, as was the frequency $\times$ regularity interaction $\left[F_{1}(1,31)=1.09, M S_{\mathrm{e}}=387, p>.30 ; F_{2}<1\right]$.

In sum, there were reliable first-fixation effects of preview and frequency. The effect of frequency was independent of preview condition. The overall pattern of the frequency $\times$ regularity results suggests that the advantage for LF regular words (or disadvantage for LF exception words) appeared only when the parafoveal preview was valid.

\section{Gaze Duration}

The gaze duration data are also shown in Table 1. A 2 (preview) $\times 2$ (frequency) $\times 2$ (regularity) ANOVA again yielded significant main effects of preview $\left[F_{1}(1,31)=\right.$ $30.11, M S_{\mathrm{e}}=1,535, p<.001 ; F_{2}(1,95)=46.65, M S_{\mathrm{e}}=$ $3,681, p<.001]$ and frequency $\left[F_{1}(1,31)=22.68, M S_{\mathrm{e}}=\right.$ $1,241, p<.001 ; F_{2}(1,95)=35.52, M S_{\mathrm{e}}=2,366, p<$ $.001]$. Readers' gaze durations were shorter with a valid $(284 \mathrm{msec})$ versus an invalid preview $(311 \mathrm{msec})$ and with a HF (287 $\mathrm{msec})$ versus a $L F$ word $(308 \mathrm{msec})$. Unlike the first-fixation data, the effect of regularity was significant $\left[F_{1}(1,31)=4.93, M S_{\mathrm{e}}=728, p<.05 ; F_{2}(1,95)=4.30\right.$, $\left.M S_{\mathrm{e}}=4,081, p<.05\right]$, as was the frequency $\times$ regularity interaction $\left[F_{1}(1,31)=5.41, M S_{\mathrm{e}}=769, p<.05\right.$; $\left.F_{2}(1,95)=4.04, M S_{\mathrm{e}}=2,263, p<.05\right]$. As with the firstfixation data, the preview $\times$ frequency interaction and the three-way interaction were nonsignificant $(F \mathbf{s}<1)$. Regularity interacted with preview in the participants analysis $\left[F_{1}(1,31)=4.85, M S_{\mathrm{e}}=736, p<.05\right]$, but was only a trend in the items analysis $\left[F_{2}(1,95)=1.88, M S_{\mathrm{e}}=\right.$ 
$3,218, p=.17]$. Again, we examined the valid and invalid preview conditions in separate 2 (frequency) $\times 2$ (regularity) ANOVAs.

In the valid preview condition, there were significant effects of frequency $\left[F_{1}(1,31)=10.60, M S_{\mathrm{e}}=1,000, p<\right.$ $\left..01 ; F_{2}(1,95)=13.40, M S_{\mathrm{e}}=2,266, p<.001\right]$ and regularity $\left[F_{1}(1,31)=12.71, M S_{\mathrm{e}}=563, p<.01 ; F_{2}(1,95)=\right.$ 9.78, $\left.M S_{\mathrm{e}}=2,262, p<.01\right]$. Gaze durations were shorter for $\mathrm{HF}(275 \mathrm{msec})$ versus LF words $(294 \mathrm{msec})$ and for regular $(277 \mathrm{msec})$ versus exception $(292 \mathrm{msec})$ words. The frequency $\times$ regularity interaction was significant by participants $\left[F_{1}(1,31)=4.30, M S_{\mathrm{e}}=728, p<.05\right]$, and marginally so by items $\left[F_{2}(1,95)=3.05, M S_{\mathrm{e}}=2,293\right.$, $p=.08]$. Contrasts revealed that LF regular and exception words differed significantly [281 vs. $306 \mathrm{msec}$, respectively; $F_{1}(1,31)=13.57, M S_{\mathrm{e}}=728, p<.001 ; F_{2}(1,95)=$ $\left.11.78, M S_{\mathrm{e}}=2,293, p<.001\right]$, while no such difference was present with HF words ( 273 vs. $278 \mathrm{msec}$, respectively; $F \mathrm{~S}<1$ ).

The gaze duration results in the invalid preview condition were similar to those in the first-fixation data. There was a significant effect of frequency $\left[F_{1}(1,31)=16.68\right.$, $M S_{\mathrm{e}}=1,081, p<.001 ; F_{2}(1,95)=16.98, M S_{\mathrm{e}}=3,271$, $p<.001]$, with gaze durations shorter for HF $(299 \mathrm{msec})$ versus $L F$ words $(323 \mathrm{msec})$. The effect of regularity was not significant $(F \mathrm{~S}<1)$, nor was the frequency $\times$ regularity interaction $\left[F_{1}(1,31)=1.61, M S_{\mathrm{e}}=774, p>.21\right.$; $\left.F_{2}<1\right]$.

Overall, the gaze duration results were similar to the first-fixation data, with significant effects of preview and frequency. In addition, there was a main effect of regularity. As before, LF exception words were fixated longer than LF regular words only when the parafoveal preview was valid. ${ }^{2}$

\section{DISCUSSION}

The results of the normal reading (valid preview) condition of our experiment are quite consistent with prior word recognition studies that have demonstrated a frequency $\times$ regularity interaction in which, in addition to an overall frequency effect, responses to LF exception words are slower than those to LF regular words (Inhoff \& Topolski, 1994; Seidenberg et al., 1984; Waters \& Seidenberg, 1985). However, since Inhoff and Topolski obtained similar effects of regularity in naming and delayed naming tasks, they raised the question of whether the naming results can be taken as evidence for early activation of phonological codes. If evidence were found with eye movement data that clearly showed regularity effects in fixation times, there would be good support for the early activation of phonological codes and for the importance of spelling-sound regularity in silent reading. As we noted in the introduction, Inhoff and Topolski's eye movement data were somewhat equivocal: While they did find a reliable main effect of regularity in first fixations, they did not observe a significant frequency $\times$ regularity interaction in their data; in addition, the regularity effect they obtained in first fixations declined to nonsignificance in their gaze duration data.

Our results clarify the situation somewhat since we found a significant 16-msec difference between LF regular and exception words in first fixations, which increased to a 25 -msec difference in gaze duration under similar conditions of normal preview. While the frequency $X$ regularity interaction was only marginally significant by participants in the first-fixation duration data, it was significant in the gaze duration data. Perhaps the most obvious explanation for why our results differ from Inhoff and Topolski's (1994) has to do with our materials: We used more than twice the number of target items, and our items were better matched across experimental conditions with regard to word class and sentence position.

One result from our study that deserves further explanation was the occurrence of a first-fixation frequency effect on targets in the invalid preview condition. A study reported by Inhoff and Rayner (1986), conceptually quite similar to ours, yielded contrary results. Inhoff and Rayner examined word frequency effects under valid and invalid preview conditions. With a valid preview, they found that LF words were fixated longer than HF words both in firstfixation and gaze duration. However, with an invalid preview, frequency effects were absent from first fixations and appeared only in gaze duration. More recently, Kennison and Clifton (1995) found that, with an invalid preview, readers' first fixations were $15 \mathrm{msec}$ longer on LF words than on HF words (similar to our 13-msec effect). Kennison and Clifton speculated on possible reasons for the difference between their results and those of Inhoff and Rayner. One difference not discussed was the manner in which preview was manipulated across studies. Inhoff and Rayner used a moving window paradigm in which preview was denied: All words to the right of the fixated word were replaced with either Xs or visually similar letters. In contrast, in the present experiment and in Kennison and Clifton's, a boundary paradigm was used in which only a single word of each sentence was altered. Perhaps readers noticed that there was typically inaccurate information to the right of fixation in Inhoff and Rayner's study and applied different processing strategies.

We are left to explain why we obtained evidence for a frequency $\times$ regularity interaction with a valid preview but not an invalid preview. As we noted in the introduction, we anticipated that we might obtain clearer evidence for the interaction in the invalid preview condition since it is arguably more analogous to word recognition studies in which participants do not receive any preview of the word before processing it. However, we obtained just the opposite result. Why might this be?

First, while an invalid preview in reading insures only foveal processing of a target, it may not be comparable to the naming or lexical decision situation, in which participants, presented with a single target, prepare a response to it alone. Henderson, Petersen, Dixon, Twilley, and Ferreira (1995) had participants saccade to a parafoveal letter string. During the saccade, a target for lexical deci- 
Table 2

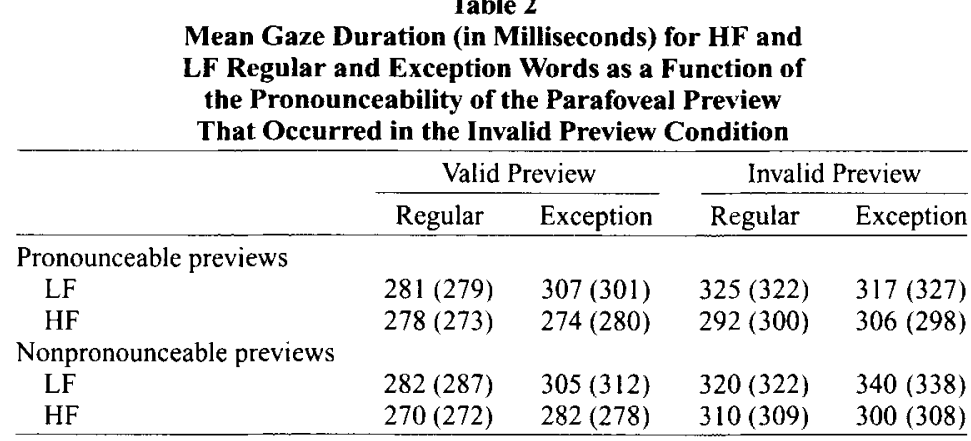

Note-Means in parentheses represent gaze durations based on the pronounceability of only the first three letters of the invalid preview. LF, low frequency; HF, high frequency.

sion replaced the string. The targets were words that contained regularly or irregularly pronounced initial trigrams (e.g., button or butane, respectively). Each target (e.g., button) was preceded by three possible parafoveal previews (e.g., button, butane, or xxxxxx). Henderson et al. found that responses to targets with phonologically regular initial trigrams were slowed more by an invalid preview, a finding that is consistent with our results. In our study, the preview $\times$ regularity interaction in both firstfixation and gaze duration indicated that the cost of an invalid preview was greater for regular than for exception words. This is consistent with the notion that phonological processing of a word begins on the prior fixation and a greater degree of such processing occurs when that word has a regular spelling-sound mapping.

Second, there is evidence from reading that phonological codes are activated parafoveally (Pollatsek, Lesch, Morris, \& Rayner, 1992). Pollatsek et al. found that readers are able to use phonological codes in integrating information across an eye movement. Specifically, they found that when readers were given a homophone as a preview (e.g., beech as a preview for beach, or chute as a preview for shoot), fixation time ${ }^{3}$ on the target word (beach or shoot) was facilitated relative to a visually similar spelling control preview (e.g., bench or chart). Their results indicate that phonological codes for the to-be-fixated word are activated in advance (see also Henderson et al., 1995). These findings, together with other related evidence (Rayner, Pollatsek, \& Binder, 1998; Rayner, Sereno, Lesch, \& Pollatsek, 1995), lead us to believe that phonological codes are activated early on in the word identification process. In our study, when preview information was invalid, the early activation of phonological codes prior to fixation was spurious and, thus, may have served to neutralize subsequent foveal phonological processing.

In order to test this explanation of the disappearance of the LF regularity effect in the invalid preview condition, we grouped our stimuli on the basis of the pronounceablity of the invalid nonword previews. ${ }^{4}$ This partition resulted in one group of 35 target sets associated with pronounceable previews and a second group of 61 target sets asso- ciated with nonpronounceable previews. The corresponding gaze duration means are shown in Table $2 .{ }^{5} \mathrm{An}$ interesting pattern emerged that is consistent with the explanation we provided. Specifically, for the pronounceable previews in the invalid preview condition, there was a significant main effect of frequency but no hint of a frequency $X$ regularity interaction. However, for the nonpronounceable previews, there was a significant effect of frequency as well as a significant frequency $\times$ regularity interaction. In another analysis, we grouped items based on the pronounceability of the first three letters of the preview. This partition resulted in one group of 57 pronounceable target sets and a second group of 39 nonpronounceable target sets, which yielded the same overall pattern of means (Table 2). Comparison of the LF regular and exception means in the invalid preview condition across the pronounceability groupings suggests that the LF regularity effect with nonpronounceable previews emerges because of a cost associated specifically with LF exception words. Nonpronounceable previews are similar in effect to orthographically and phonologically "strange" words. Just as exposure to "strange" words increases the likelihood of generating LF regularity effects (see, e.g., Waters \& Seidenberg, 1985), the presence of nonpronounceable previews on a local level can similarly create greater phonological awareness and subsequent costs in foveal processing of LF exception targets. When nonword previews are pronounceable and generally regular in their orthography and phonology, early phonological processing does not elicit a conflicting influence.

We believe the present experiment has provided clear evidence of the frequency $\times$ regularity interaction in normal reading. First fixations and gaze durations on $\mathrm{HF}$ regular and exception words did not differ, but they were significantly longer on LF exception than on LF regular words. When readers were denied parafoveal access to a word, the LF regularity difference disappeared; we provided an account of this in terms of parafoveal phonological processing. We conclude that phonological codes are activated early enough under normal viewing conditions to facilitate reading. 


\section{REFERENCES}

Balota, D. A., Pollatsek, A., \& Rayner, K. (1985). The interaction of contextual constraints and parafoveal visual information in reading. Cognitive Psychology, 17, 364-390.

Bauer, D. W.. \& Stanovich, K. E. (1980). Lexical access and the spelling-to-sound regularity effect. Memory \& Cognition, 8, 424432.

BeCKeR, W. (1989). Metrics. In R. H. Wurtz \& M, E. Goldberg (Eds.), The neurobiology of saccadic eye movements (pp. 13-67). New York: Elsevier.

Blanchard, H. E., Pollatsek, A., \& Rayner, K. (1989). The acquisition of parafoveal word information in reading. Perception \& Psychophysics, 46, 85-94.

Francis, W. N., \& KuČERA, H. (1982). Frequency analysis of English usage: Lexicon and grammar. Boston: Houghton Mifflin.

GLUSHKO, R. (1979). The organization and activation of orthographic knowledge in reading aloud. Journal of Experimental Psychology: Human Perception \& Performance, 5, 674-691.

Henderson, J. M., \& Ferreira, F. (1990). Effects of foveal processing difficulty on the perceptual span in reading: Implications for attention and eye movement control. Journal of Experimental Psychology: Learning, Memory, \& Cognition, 16, 41 7-429.

Henderson, J. M., Petersen, A., Dixon, P., Twilley, L. C., \& FerREIRA, F. (1995). Evidence for the use of phonological codes during transsaccadic word recognition. Journal of Experimental Psychology: Human Perception \& Performance, 21, 82-97.

HYöNÄ. J., \& OLSON, R. K. (1995). Eye fixation patterns among dyslexic and normal readers: Effects of word length and word frequency. Journal of Experimental Psychology: Learning, Memory. \& Cognition, 21, 1430-1440.

INHOFF, A. W. \& RAYNER, K. (1986). Parafoveal word processing during eye fixations in reading: Effects of word frequency. Perception \& Psychophysics, 40, 431-439

INHOFF, A. W.. \& TOPOLSKI, R. (1994). Use of phonological codes during eye fixations in reading and in on-line and delayed naming tasks. Journal of Memory \& Language, 33, 689-713.

Just, M. A., \& CARPENTER, P. A. (1980). A theory of reading: From eye fixations to comprehension. Psychological Review, 87, 329-354.

Kennison, S. M., \& Clifton, C., JR. (1995). Determinants of parafoveal preview benefit in high and low working memory capacity readers: Implications for eye movement control. Journal of Experimental Psychology: Learning. Memory, \& Cognition, 21, 68-81.

Mayzner, M. S., \& TRessel., M. E. (1965). Tables of single-letter and digram frequency for various word-length and letter-position combinations. Psychonomic Monograph Supplements, 1, 13-32.

Pollatsek, A., Lesch, M. F., Morris, R. K., \& Rayner, K. (1992). Phonological codes are used in integrating information across saccades in word identification and reading. Journal of Experimental Psychology: Human Perception \& Performance, 18, 148-162.

RAYNER, K. (1975). The perceptual span and peripheral cues in reading. Cognitive Psychology, 7, 65-81.

RAYNER, K., \& DUFFY, S. A. (1986). Lexical complexity and fixation times in reading: Effects of word frequency, verb complexity, and lexical ambiguity. Memory \& Cognition, 14, 191-201.

Rayner, K., Pollatsek, A., \& Binder, K. S. (1998). Phonological codes and eye movements in reading. Journal of Experimental Psychologw: Learning, Memory, \& Cognition, 24, 476-497.

RAYNER, K., \& RANEY, G. E. (1996). Eye movement control in reading and visual search: Effects of word frequency. Psychonomic Bulletin \& Review, 3, 245-248.

Rayner, K., Sereno, S. C., Lesch, M. F., \& Pollatsek, A. (1995).
Phonological codes are automatically activated during reading: Evidence from an eye movement priming paradigm. Psychological Science, 6, 26-30.

Rayner, K., Sereno, S. C., \& Raney, G. E. (1996). Eye movement control in reading: A comparison of two types of models. Journal of Experimental Psychology: Human Perception \& Performance, 22, $1188-1200$.

Rayner, K., Well, A. D., Pollatsek, A., \& Bertera, J. H. (1982). The availability of useful information to the right of fixation in reading. Perception \& Psychophysics, 31, 537-550.

SCHILling, H. E. H., Rayner, K., \& ChUmbley, J. I. (1998). Comparing naming, lexical decision, and eye fixation times: Word frequency effects and individual differences. Memory \& Cognition, 26, 1270-1281.

Seidenberg, M. S., Waters, G. S., Barnes, M. A., \& Tanenhaus, M. K. (1984). When does irregular spelling or pronunciation influence word recognition? Journal of Verbal Learning \& Verbal Behavior, 22, 383404.

SERENO, S. C. (1992). Early lexical effects when fixating a word in reading. In K. Rayner (Ed.), Eye movements and visual cognition: Scene perception and reading (pp. 304-316). New York: Springer-Verlag.

Sereno, S. C., Rayner, K., \& Posner, M. I. (1998). Establishing a time-line of word recognition: Evidence from eye movements and event-related potentials. NeuroReport, 9, 2195-2200.

Stanovich, K. E., \& Bauer, D. W. (1978). Experiments on the spelling-to-sound regularity effect in reading. Memory \& Cognition, 6, 410-415.

Waters, G. S., \& SeidenberG, M. S. (1985). Spelling-sound effects in reading: Time-course and decision criteria. Memory \& Cognition, 13, $557-572$.

\section{NOTES}

1. Other standard eye movement measures, such as total fixation time (the sum of all fixations on a word, including those from regressions), spillover time (the duration of the fixation immediately following the fixation[s] on the target word), and target skipping rates, were also examined. In general, lexical effects found in these measures dimly mirror those found in first-fixation and gaze duration. We found an overall effect of frequency that was significant in total fixation time and marginal in spillover time. Readers rarely skipped the target in the invalid preview condition; when they did, they immediately regressed to it. In the valid preview condition, there was a marginal effect of frequency with HF words skipped more often than LF words.

2. It was pointed out in the review process that the LF exception word list included a few homophones (e.g., isle, pear, or cruise). It was also pointed out that several "strange" words (i.e., words that are orthographically as well as phonologically irregular; see Seidenberg et al., 1984) were included in the LF exception list (e.g., yacht, feud, or choir). We eliminated these items and performed separate analyses. When an item (e.g., yacht) was removed from an analysis, the remaining items from that set (e.g., shack, chair, and knife) were also eliminated. In both analyses, the same pattern of results held for first-fixation and gaze duration as reported for the entire stimulus list.

3. Interestingly, Pollatsek et al. (1992) found a stronger effect on firstfixation than on gaze duration.

4. We thank an anonymous reviewer for suggesting this analysis 5. In Table 2, when weighted averages across the two groups are taken in each condition, the resulting means represent the item means and are slightly different from the participant means reported in Table 1. It is also relevant to note that there were no differences in the pattern of valid preview means across the two groups; preview pronounceability is an arbitrary division within this condition. 


\section{APPENDIX}

Experimental sentences and target words. The letter strings in parentheses are the invalid parafoveal previews that initially appeared in the target region on half the trials. The blank indicates one of four possible targets listed to the right. The target conditions are low-frequency (LF) and high-frequency (HF) regular (Reg) and exception (Exc) words.

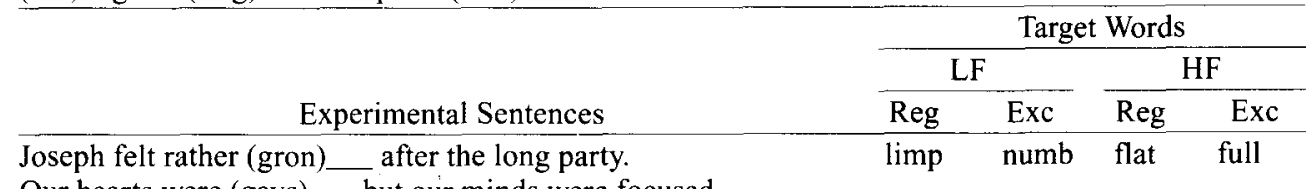

Our hearts were (gavs)__ but our minds were focused.

I think my brain was totally (tase)__ before that exam.

The breakup had left Melissa (dand) with all that sadness.

Apparently, those (whle)__ children on the bus were orphans._meek deaf dark good

It seems that the (lusr)__ ones are rarely recognized.

Anger had gotten the better of his (civr) brother that day.

Alexander's (vule)__ sister tried to apologize to him.

The animal's (lnts)__ was bruised from abuse. rump hoof back foot

The sore on Tam-Tam's (tnam) _ had swollen to twice its size.

The antelope had an injured (sete)__ from fighting other males.

The creature could not rest on its (lhir)__ for very long.

Suddenly, a large (mhtm)__ appeared from nowhere._crab wasp face bear

It's hard to confront an angry (gpmt)_ without warning.

We avoided looking right at the (toly)_ because it scared us.

A happy-looking (thid)___ is not to be trusted.

We listened for noises coming from the (frls)__ until morning. dock tomb hall door

Flashes from the shadowy (beih) __ sent shivers up my spine.

When the (sevt)__ was reopened, we were surprised at the sight.

After the (oirt)__ was examined, all fears were laid to rest.

It was a lonely (fhmt)__during those eight days.
Ellen dreamed of an exciting (ched)__to escape the daily grind.

hike isle race tour

An unusual (kesk) _ seemed like a fine alternative to tax forms.

Many had signed up to go to the scheduled (nreh) that weekend.

At that moment, our trivial (hlvn)__ wasn't fun anymore.
The officials wanted the disruptive (riam)__ to be terminated.

The long-lasting (thsg)__ finally ended.

The newly created (shtr)__ was unpopular with my friends.

He clutched the thin (beas)__ so hard his knuckles turned white. cane wand club post

The performer madly swung the long (trlm)__ back and forth.

Grampa used the wooden (feml) _ to prop up his car hood.

We found an ancient (fhvh)

in Aunt Annie's attic.

Harriet dangled the dirty (tasd) _ in front of his face.

The black (tait)__ had been left in the room.

Mary returned to retrieve Ken's (latd)__ that was missing.

There are many uses for an old (kvah)_ if one is inventive.

When she returned, Sharon's (shle)__ was infested with insects. fern pear land wood

Wayne found that his precious (thme) _ had been stolen.

George gave his most valuable (shse)__ to his partner.

Rebecca sold her best (thie) _ for a cheap price.

Mr. Thorpe filled the extra (anrd)__ with great purpose.

Eric approached the chosen (eutd)__ with trepidation.

Tony used the entire (grol)__ to no avail.

Mike wasted the whole (yesm) _ and then regretted it.

Every little (ovek)__ in this world deserves happiness.

The priest said that even the ugliest (tlis)__ is worth saving.

My mother would help any lost (brtm)__ if she were able to.

Reverend Bob said that every (whed)__ shall seek forgiveness.

cult feud game work

sock comb file shoe

cask pint week hour

lamb life soul 


\begin{tabular}{|c|c|c|c|c|}
\hline \multirow[b]{3}{*}{ Experimental Sentences } & \multicolumn{4}{|c|}{ Target Words } \\
\hline & \multicolumn{2}{|r|}{ LF } & \multicolumn{2}{|c|}{$\mathrm{HF}$} \\
\hline & Reg & Exc & Reg & Exc \\
\hline $\begin{array}{l}\text { Jason wore those (thlts)_ pants of his to the reception. } \\
\text { The poster with the (shile)_design on it was on sale. } \\
\text { The boutique's display of (motso) clothes amazed us. } \\
\text { Donna had spotted that (thirl)__ shirt from across the mall. }\end{array}$ & peach & plaid & beach & great \\
\hline $\begin{array}{l}\text { Lori could not get that awful (whuhl)__ stain out of her blouse. } \\
\text { The sinister wizard added a little (shret)_ to his potion. } \\
\text { The formula required distilled (whdet)_ extract to be potent. } \\
\text { One small (cmnah)__smudge on Tom's sleeve proved him guilty. }\end{array}$ & grape & onion & grass & blood \\
\hline $\begin{array}{l}\text { We inherited a worthless (leony)__ from our grandmother. } \\
\text { Such a small (prgln)_ was too expensive. } \\
\text { Everything but Elliot's (elotd)__ was destroyed in the fire. } \\
\text { The beautiful (bienh)__ came in handy for the banquet. }\end{array}$ & shack & yacht & chair & knife \\
\hline $\begin{array}{l}\text { People stepped into the dilapidated (pumse)__ in single file. } \\
\text { Floodlights lit up the famous (ntneh)_ for the press. } \\
\text { The obsolete (atiud)__ had not functioned for years. } \\
\text { Spectators gathered around the new (femle)__ in anticipation. }\end{array}$ & shaft & choir & train & court \\
\hline $\begin{array}{l}\text { Mother said it was inappropriate to (serwn)__ in public places. } \\
\text { We wanted to (salgs)_ too, but we thought people would stare. } \\
\text { Whenever we would (rlasd)__a lot, my brother would giggle. } \\
\text { If we'd (drase)__ during the performance, we'd be kicked out. }\end{array}$ & cheer & cough & point & touch \\
\hline $\begin{array}{l}\text { Kathy could (girtg)_ her boyfriend if she especially wanted to. } \\
\text { Steve didn't want to really (ctnuy)_ his friend that night. } \\
\text { If Ted needed to really (alers)_someone, he'd go to the bars. } \\
\text { Jim's parents found it hard to actually (taemy)_ their own son. }\end{array}$ & blast & shove & reach & doubt \\
\hline $\begin{array}{l}\text { The cruel (slouny)_ frightened the children. } \\
\text { Such an evil (crevth)_ should be combatted at all costs. } \\
\text { The imaginary (dhcich)_ suddenly materialized to our horror. } \\
\text { The strange (refiol)__ had made the community uneasy and afraid. }\end{array}$ & hunter & plague & farmer & threat \\
\hline $\begin{array}{l}\text { The homeless sought out the warm (rmotet)__ on freezing days. } \\
\text { The abandoned (blngne)__ was a favorite hangout for the gang. } \\
\text { The runaway returned to the familiar (tromer)_ that night. } \\
\text { The brand new (inthlr)___ was finally being used. }\end{array}$ & subway & hearth & church & school \\
\hline $\begin{array}{l}\text { Josh and I will never forget that (whrith)_ where we first met. } \\
\text { The extraordinary (mieltr)_ was the inspiration for the novel. } \\
\text { The final (haokcn)_ turned out to be the best. } \\
\text { The dangerous (litneg)_ did not please everyone. }\end{array}$ & summit & cruise & stream & island \\
\hline $\begin{array}{l}\text { Jo's remarkable (dreasd)__ was the subject of much conversation. } \\
\text { Ed's conspicuous (sunitm)__ caused strangers to take note. } \\
\text { Scott's prominent (crekse___ was disproportionate. } \\
\text { The topic of Oliver's (stugnd)__always seemed to arise. }\end{array}$ & temper & wealth & throat & height \\
\hline $\begin{array}{l}\text { Gordon stumbled onto the (shalnr)_ quite accidentally. } \\
\text { Dick avoided the (feadsn)_ whenever possible. } \\
\text { The agent even searched the (bumoun)__for the missing gems. } \\
\text { We could see the (weatos)__from behind the bushes. }\end{array}$ & casket & trough & market & police \\
\hline $\begin{array}{l}\text { Everyone thought that the (tampct)__ was obvious. } \\
\text { There was one (thidth)__ that could not be accounted for. } \\
\text { The peculiar (nicknt)__ caught everyone's attention. } \\
\text { The original (pomuls)__ faded in due course of time. }\end{array}$ & stripe & bruise & reason & answer \\
\hline
\end{tabular}

